\title{
What the impact of the economic crisis on the Brazilian's lifestyle between 2013 and 2016? A long- term trend cross-sectional study.
}

Sonny Állan Bezerra ( $\sim$ sonnybezerra@gmail.com )

Universidade Federal do Maranhao https://orcid.org/0000-0002-6600-777X

Denilson Menezes Santos

Universidade Federal do Maranhao

Michele Maria Oliveira

Universidade Federal do Maranhao

Claudia Vanisse Costa

Universidade Federal do Maranhao

Elaynne de Oliveira

Universidade Federal do Maranhao

Levy Silva Rezende

Universidade Federal do Maranhao

Emanuel Péricles Salvador

Universidade Federal do Maranhao

Research

Keywords: Economic Crisis. Public Health. Lifestyle. Brazil.

Posted Date: May 5th, 2020

DOl: https://doi.org/10.21203/rs.3.rs-26007/v1

License: (9) (i) This work is licensed under a Creative Commons Attribution 4.0 International License.

Read Full License 


\section{Abstract}

Background: Brazil has been going through a period of economic crisis since 2015 and the impact on health indicators and the quality of life of the most recent crisis is unclear. This study sought to establish a relationship between the impact of the economic crisis experienced by Brazil during the period 2013-2016 and the lifestyle of adult populations in the 27 capitals of the Brazilian state.

Results: According to the binary logistic regression model, at least completing secondary education increases the probability of individuals presenting higher LS by $4.9 \%(\mathrm{OR}=1,049,95 \% \mathrm{Cl} 1,029-1,070)$; being involved in some type of relationship decreases the probability of presenting a higher LS by $5.3 \%$ $(\mathrm{OR}=0.947,95 \% \mathrm{Cl} 0.029-0.965)$; having an adequate body mass index increases LS by $27.3 \%$ $(\mathrm{OR}=1.273,95 \% \mathrm{Cl} 1,245.10 .10)$. Living in a city with a lower unemployment rate increases the probability of having a higher LS score by $3.8 \%(\mathrm{OR}=1,038,95 \% \mathrm{Cl} 1,012-1.064)$; living in a city with a more basic food basket decreases the probability of having a higher LS score by $5.4 \%(O R=0.946,95 \% \mathrm{Cl}$ $0.910-0.982)$. Presenting higher yields decreases the probability of having a higher LS by $12 \%(\mathrm{OR}=0.880$, $95 \% \mathrm{Cl} 0.860-0.900)$. In addition, there was an increase in the percentage of leisure-time PA in 2015 (20.9\%), followed by a decrease to 18.1\% in 2016, after a stabilization period in 2013 (19.5\%) and 2014 (19.6\%). The physical exercise showed a steady annual increase, with a score of $49.6 \%$ in 2013 , followed by $50.9 \%$ and $51.9 \%$ in 2014 and 2015 , respectively, and ending with $54.5 \%$ in 2016 . The "Watch TV $5 x$ per week" indicator recorded a sharp drop between 2013 (27.9\%) and 2015 (22.7\%), as well as the consumption of soft drinks, which went from stable values in 2013 (19.5\%) and 2014 (19\%) 17.3\% in 2015.

Conclusion: In the case of Brazil, the economic crisis initially started in 2015 had a negative impact on the population over time, but these effects were only observed in the second year of crisis, being preceded by a temporary improvement of indicators.

\section{Background}

Brazil has the largest economy in South America. This country with continental dimensions has been going through a period of economic crisis since 2015 . This has significantly affected essential services such as public safety, education, and health, which have made progress in recent decades. The following are some milestones in the field of health: the implementation of the Unified Health System (1990), the Family Health Strategy (1994), and the National Health Promotion Policy (2006).

In addition to a decline in chronic malnutrition, Brazilian public health policies have resulted in a significant decrease in smoking habits, gaining international attention for the combat against tobacco use ${ }^{1}$. According to Malta et al. ${ }^{1}$, many of these findings can be explained by the broadening of the social protection network of the Brazilian state in recent decades with the establishment of family health support centers (NASF, “Núcleos de Apoio a Saúde da Família”); the National Food and Nutritional Surveillance System (SISVAN, "Sistema Nacional de Vigilância Alimentar e Nutricional”); and the 
implementation of the Food Guide for the Brazilian Population, in addition to the financing of municipal projects to encourage physical activity such as the Health Academy Program, which are examples of state investment in [its citizens'] quality of life.

However, promoting a physically active lifestyle is a difficult problem to solve. Data from the research conducted by Malta et al ${ }^{2}$ in 2006, obtained by Telephone Survey on Surveillance of Chronic Diseases' Risk and Protective Factors (VIGITEL), pointed to an average $29.2 \%$ prevalence of sedentary lifestyle in Brazilian capitals. In another study, with data from 2013, obtained by the National Health Survey, $46 \%$ of the Brazilian population was classified as insufficiently active ${ }^{3}$, indicating the need for effective state action to promote active and healthy lifestyles.

Meanwhile, Brazilians have experienced strong economic crises in the last three decades, all of which have a great social impact. Furthermore, there is a lack of clarity regarding the impact on health indicators and quality of life of the most recent crisis, which started at the end of 2014, peaking between 2015 and 2016, and is still ongoing.

Nevertheless, the investigation of associations between economic crises and health and lifestyle indicators gained notoriety as an interest of several researchers and in different countries as a population base in the USA, Canada, Italy, Greece, and South Korea ${ }^{4-10}$.

Thus, this study aimed to establish a relation between the impact of the economic crisis experienced by Brazil during the 2013-2016 period and the lifestyle of the adult populations of the 27 Brazilian state capitals, focusing on physical activity, vegetable consumption, smoking, and alcohol consumption and their connection with macro and microeconomic variables.

\section{Methodology}

\section{Data}

Lifestyle data were accessed through the annual database of the VIGITEL ("Vigilância de fatores de risco e proteção para Doenças Crônicas por inquérito telefônico"), covering the period from 2013 to 2016.

VIGITEL seeks to identify risk variables for chronic diseases and socioeconomic and demographic information from all 26 Brazilian state capitals and the Federal District annually. The final sample consisted of 190,000 individuals.

Data pertaining to socioeconomic variables was collected through inquiries made to the databases of DataSUS ${ }^{11}$; IBGE ${ }^{12}$; and Central Bank of Brazil ${ }^{13}$. Data such as GDP per capita, formal and informal work, public debt, vacancy rate, average staple foods basket value, per capita income, Gini index, average employee income, and occurrence of manslaughter were collected from the 26 state capitals and the Federal District. In all, 69 variables make up the database formatted from the inclusion and association resulting from the inquiries described. 


\section{Lifestyle Score (Is)}

For the analysis of lifestyle, we opted for the creation of a "Lifestyle Score" (LS) based on the sum of the following indicators: physical activity during leisure time (yes $=1$; no $=0$ );practicing physical exercises (yes = 1; no = 0); active form of transport to work (yes = 1 no = 0 ); active in terms of general transit (yes = 1 ; no $=0$ ); regular consumption of fruits (yes $=1 ; n o=0)$; regular consumption of vegetables and legumes (yes $=1 ;$ no $=0)$; regular consumption of beans (yes $=1 ;$ no $=0)$; smoking ( $n o=1$; yes $=0)$; excessive consumption of alcohol ( $\mathrm{no}=1$; yes $=0$ ); and excessive television viewing time (no $=1$; yes $=0$ ). Thus, the minimum and maximum score were 0 and 11 , respectively. In the case of micro and macroeconomic indicators, we used the strategy of dividing the data according to each variable's median, defining them as "higher value" and "lower value."

\section{Statistical analysis}

Descriptive statistics (i.e., means and standard deviations) of macro and microeconomic variables and relative values (i.e., absolute frequency, relative and $95 \% \mathrm{Cl}$ ) of socioeconomic and lifestyle variables were performed. For the statistical treatment of the collected data, we opted for the use of binary logistic regression analysis, considering the LS as a dependent variable and the following as independent variables: vacancy rate, staple foods basket value, average worker income, GINI index of inequality and years (2013-2016). The following were used as covariates: years of schooling, marital status (accompanied), BMI (body mass index), gender, and capital region (north, northeast, midwest, southeast, south).

\section{Results}

\section{Behavior of socioeconomic indicators}

The descriptive analysis of the socioeconomic indicators (Table 1) reveals stability in the schooling indicator between the years 2013 and 2016. The same occurs with the Gini index of inequality, with a percentage variation in the standard deviation, although there is a numerical decrease in the years 2015 and 2016 (0.48) in comparison to 2013 (0.50), which could indicate a slight downward trend in mean inequality but without statistical relevance. Despite a slight increase between 2013 and 2015, workers average income decreased again in 2016.

Conversely, the average value of the staple foods basket in the capitals showed a strong progression behavior, indicating an increase in inflation during the analyzed period. Unemployment decreased between 2013 (8.5\%) and $2015(7.71 \%)$ but increased again, settling at 0.57 percentage points above the 2013 figure. 
Table 1

Brazilian adult population socioeconomic indicators from 2013 to 2016

\begin{tabular}{|llll|}
\hline Variables & Year & Mean & DP \\
\hline Education (years) & 2013 & 5.01 & 1.43 \\
\cline { 2 - 4 } & 2014 & 4.97 & 1.46 \\
\hline 2015 & 5.04 & 1.46 \\
\hline Unemployment & 2016 & 5.03 & 1.52 \\
(rate\%) & 2013 & 8.50 & 2.70 \\
\hline Staple Foods Basket & 2014 & 7.81 & 2.69 \\
\hline (R\$) & 2015 & 7.71 & 2.96 \\
\hline 2016 & 9.07 & 2.41 \\
\hline Average income & 2014 & 287.35 & 27.13 \\
\hline (RS) & 2015 & 299.48 & 29.76 \\
\hline (p.p.) & 2016 & 332.14 & 31.83 \\
\hline 2013 & 2742.82 & 720.71 \\
\hline 2014 & 0.50 & 0.03 \\
\hline 2014 & 0.49 & 0.03 \\
\hline 2015 & 0.48 & 0.03 \\
\hline & 2016 & 0.48 & 0.03 \\
\hline & 2016 & 2769.75 & 700.10 \\
\hline
\end{tabular}

Analyzing the data related to lifestyle (Table 2 and Table 2.1), the percentage of individuals who reported not practicing sufficient physical activity during leisure time remained stable at $80.5 \%$ between the years 2013 and 2016, with a slight percentage decrease in the year of 2015 (79.1\%). Even greater is the percentage of individuals who said they did not practice enough physical activity in transportation: $91 \%$ in the years 2013 and $2014,91.6 \%$ in 2015 and $90.2 \%$ in 2016 . 
Table 2

Descriptive lifestyle data

\begin{tabular}{|c|c|c|c|c|c|c|}
\hline \multirow[t]{2}{*}{ Variables } & \multirow[t]{2}{*}{ Year } & \multirow[t]{2}{*}{ Response } & \multirow{2}{*}{$\begin{array}{l}\text { Absolute } \\
\text { frequency }\end{array}$} & \multirow{2}{*}{$\begin{array}{l}\text { Frequency } \\
\text { (\%) }\end{array}$} & \multicolumn{2}{|l|}{ Cl 95\% } \\
\hline & & & & & Lower & Higher \\
\hline \multirow{8}{*}{$\begin{array}{l}\text { Sufficient physical activity during } \\
\text { leisure time }\end{array}$} & 2013 & No & 41047 & 80,5 & 80,20 & 80,86 \\
\hline & & Yes & 9928 & 19,5 & 19,10 & 19,82 \\
\hline & 2014 & No & 28072 & 80,6 & 80,20 & 81,00 \\
\hline & & Yes & 6747 & 19,4 & 19,00 & 19,80 \\
\hline & 2015 & No & 42840 & 79,1 & 78,70 & 79,40 \\
\hline & & Yes & 11334 & 20,9 & 20,60 & 21,30 \\
\hline & 2016 & No & 42836 & 80,5 & 80,20 & 80,80 \\
\hline & & Yes & 10374 & 19,5 & 19,20 & 19,80 \\
\hline \multirow{8}{*}{$\begin{array}{l}\text { Sufficient physical activity while } \\
\text { commuting }\end{array}$} & 2013 & No & 46440 & 91,1 & 90,85 & 91,35 \\
\hline & & Yes & 4535 & 8,9 & 8,64 & 9,14 \\
\hline & 2014 & No & 31723 & 91,1 & 90,81 & 91,40 \\
\hline & & Yes & 3096 & 8,9 & 8,59 & 9,19 \\
\hline & 2015 & No & 49617 & 91,6 & 91,35 & 91,82 \\
\hline & & Yes & 4557 & 8,4 & 8,17 & 8,64 \\
\hline & 2016 & No & 47999 & 90,2 & 89,95 & 90,46 \\
\hline & & Yes & 5211 & 9,8 & 9,54 & 10,04 \\
\hline \multirow[t]{8}{*}{ Exercise } & 2013 & No & 25676 & 50,4 & 49,93 & 50,80 \\
\hline & & Yes & 25299 & 49,6 & 49,19 & 50,06 \\
\hline & 2014 & No & 17106 & 49,1 & 48,60 & 49,65 \\
\hline & & Yes & 17713 & 50,9 & 50,34 & 51,39 \\
\hline & 2015 & No & 25236 & 46,6 & 46,16 & 47,00 \\
\hline & & Yes & 28938 & 53,4 & 52,99 & 53,83 \\
\hline & 2016 & No & 24112 & 45,3 & 44,89 & 45,74 \\
\hline & & Yes & 29098 & 54,7 & 54,26 & 55,11 \\
\hline \multirow[t]{2}{*}{ Active routes } & 2013 & No & 41222 & 80,9 & 80,52 & 81,21 \\
\hline & & Yes & 9753 & 19,1 & 18,79 & 19,47 \\
\hline
\end{tabular}




\begin{tabular}{|c|c|c|c|c|c|c|}
\hline & 2014 & No & 28207 & 81,0 & 80,59 & 81,42 \\
\hline & & Yes & 6612 & 19,0 & 18,57 & 19,40 \\
\hline & 2015 & No & 44813 & 82,7 & 82,40 & 83,04 \\
\hline & & Yes & 9361 & 17,3 & 16,96 & 17,59 \\
\hline & 2016 & No & 43603 & 81,9 & 81,61 & 82,27 \\
\hline & & Yes & 9607 & 18,1 & 17,72 & 18,38 \\
\hline \multirow{8}{*}{$\begin{array}{l}\text { Watching TV for more than } 3 \\
\text { hours in five or more days }\end{array}$} & 2013 & No & 14234 & 27,9 & 27,53 & 28,31 \\
\hline & & Yes & 36741 & 72,1 & 71,68 & 72,46 \\
\hline & 2014 & No & 8609 & 24,7 & 24,27 & 25,18 \\
\hline & & Yes & 26210 & 75,3 & 74,82 & 75,73 \\
\hline & 2015 & No & 12292 & 22,7 & 22,33 & 23,04 \\
\hline & & Yes & 41882 & 77,3 & 76,95 & 77,66 \\
\hline & 2016 & No & 13864 & 26,1 & 25,68 & 26,43 \\
\hline & & Yes & 39346 & 73,9 & 73,57 & 74,31 \\
\hline
\end{tabular}

Watching television for more than three hours on five or more days of the week was reported by reported by $72.1 \%$ of individuals in $2013,75.3 \%$ in $2014,77.3 \%$ in 2015 and $73.9 \%$ in 2016 . As for the active route, only $19 \%$ and $19.1 \%$ said they performed in 2013 and 2014, respectively; $17.3 \%$ in 2015 and $18.1 \%$ in 2016. On the other hand, there was a progressive increase in the number of individuals who claimed to perform some type of physical exercise during the annual series: $49.6 \%$ in $2013 ; 50.9 \%$ in $2014 ; 53.4 \%$ ?? in 2015 and $54.7 \%$ in 2016.

The consumption of vegetables on five or more days a week remained stable in the years $2013(56.6 \%)$, 2014 (55.1\%) and 2015 (56.2\%), decreasing to 54.5\% in the following year. Fruit consumption on five or more days of the week was high, with $68.8 \%$ and $68.8 \%$ in the years 2013 and 2014, respectively, with an increase to $71 \%$ in 2015 and a decrease in 2016 (67.6\%). 


\begin{tabular}{|c|c|c|c|c|c|c|}
\hline \multirow[t]{2}{*}{ Variables } & \multirow[t]{2}{*}{ Year } & \multirow[t]{2}{*}{ Response } & \multirow{2}{*}{$\begin{array}{l}\text { Absolute } \\
\text { frequency }\end{array}$} & \multirow{2}{*}{$\begin{array}{c}\begin{array}{c}\text { Frequency } \\
(\%)\end{array} \\
\end{array}$} & \multicolumn{2}{|c|}{ CI $95 \%$} \\
\hline & & & & & Lower & Higher \\
\hline \multirow{8}{*}{ Consuming fruits five or more days of the week } & 2013 & No & 15904 & 31,2 & 30,79 & 31,60 \\
\hline & & Yes & 35071 & 68,8 & 68,39 & 69,20 \\
\hline & 2014 & No & 11004 & 31,6 & 31,11 & 32,09 \\
\hline & & Yes & 23815 & 68,4 & 67,90 & 68,88 \\
\hline & 2015 & No & 15689 & 29,0 & 28,57 & 29,34 \\
\hline & & Yes & 38485 & 71,0 & 70,65 & 71,42 \\
\hline & 2016 & No & 17214 & 32,4 & 31,95 & 32,74 \\
\hline & & Yes & 35996 & 67,6 & 67,25 & 68,04 \\
\hline \multirow{8}{*}{ Consuming vegetables five or more days per week } & 2013 & No & 22120 & 43,4 & 42,96 & 43,82 \\
\hline & & Yes & 28855 & 56,6 & 56,17 & 57,03 \\
\hline & 2014 & No & 15628 & 44,9 & 44,36 & 45,40 \\
\hline & & Yes & 19191 & 55,1 & 54,59 & 55,63 \\
\hline & 2015 & No & 23734 & 43,8 & 43,39 & 44,23 \\
\hline & & Yes & 30440 & 56,2 & 55,77 & 56,60 \\
\hline & 2016 & No & 24223 & 45,5 & 45,10 & 45,94 \\
\hline & & Yes & 28987 & 54,5 & 54,05 & 54,89 \\
\hline \multirow{8}{*}{$5 \mathrm{x} /$ week consumption of beans } & 2013 & No & 20727 & 40,7 & 40,23 & 41,08 \\
\hline & & Yes & 30248 & 59,3 & 58,91 & 59,76 \\
\hline & 2014 & No & 13862 & 39,8 & 39,29 & 40,32 \\
\hline & & Yes & 20957 & 60,2 & 59,67 & 60,70 \\
\hline & 2015 & No & 22343 & 41,2 & 40,82 & 41,65 \\
\hline & & Yes & 31831 & 58,8 & 58,34 & 59,17 \\
\hline & 2016 & No & 23776 & 44,7 & 44,26 & 45,10 \\
\hline & & Yes & 29434 & 55,3 & 54,89 & 55,73 \\
\hline \multirow[t]{8}{*}{$5 \mathrm{x} /$ week consumption of soft drinks } & 2013 & No & 42355 & 83,1 & 82,76 & 83,41 \\
\hline & & Yes & 8620 & 16,9 & 16,58 & 17,23 \\
\hline & 2014 & No & 29547 & 84,9 & 84,48 & 85,23 \\
\hline & & Yes & 5272 & 15,1 & 14,76 & 15,51 \\
\hline & 2015 & No & 6624 & 12,2 & 11,93 & 12,52 \\
\hline & & Yes & 47550 & 87,8 & 87,47 & 88,06 \\
\hline & 2016 & No & 47490 & 89,3 & 88,98 & 89,51 \\
\hline & & Yes & 5720 & 10,7 & 10,48 & 11,01 \\
\hline
\end{tabular}

Table 2.1

Descriptive lifestyle data

\section{Lifestyle Score (Is) And Correlations With Socioeconomic Indicators}

According to the binary logistic regression model (Table 3), at least completing high school increases the chance of individuals presenting a higher $\mathrm{LS}$ by $4.9 \%(\mathrm{OR}=1.049,95 \% \mathrm{Cl} 1.029-1.070)$; being involved in some type of relationship decreases the chance of presenting a higher LS by $5.3 \%(\mathrm{OR}=0.947,95 \% \mathrm{Cl}$ 
$0.029-0.965)$; and an adequate body mass index increases the LS by $27.3 \%(\mathrm{OR}=1.273,95 \% \mathrm{Cl} 1.245-$ 1.301).

As for the regions of the country, with reference to the northern region, with the lowest $\mathrm{HDI}$, an upward trend was shown in terms of the chance of achieving a higher LS score as the regional HDI increased $(p<$ 0.001); all regions showed statistically significant associations with the southeastern region, with the highest $\mathrm{HDI}$, evincing $59.8 \%$ more chances of obtaining higher LS. 
Table 3

Logistic regression model correlations between lifestyle and socioeconomic indicators 2013-2016

\begin{tabular}{|c|c|c|c|c|c|c|}
\hline \multirow[b]{2}{*}{ Variables } & \multirow[t]{2}{*}{$\beta$} & \multirow{2}{*}{$\begin{array}{l}\text { Standard } \\
\text { Error }\end{array}$} & \multirow[t]{2}{*}{$p$} & \multirow[t]{2}{*}{ OR } & \multicolumn{2}{|l|}{$95 \% \mathrm{Cl}$} \\
\hline & & & & & Lower & Higher \\
\hline At least high school & 0.048 & 0.010 & $<.001$ & 1.049 & 1.029 & 1.070 \\
\hline $\begin{array}{l}\text { Married, in a stable union, or } \\
\text { dating }\end{array}$ & -0.055 & 0.010 & $<.001$ & 0.947 & 0.929 & 0.965 \\
\hline Eutrophic & 0.241 & 0.011 & $<.001$ & 1.273 & 1.245 & 1.301 \\
\hline Region of the country (ref. North) & & & $<.001$ & & & \\
\hline Northeast & 0.046 & 0.021 & 0.030 & 1.047 & 1.004 & 1.092 \\
\hline South & 0.181 & 0.022 & $<.001$ & 1.198 & 1.148 & 1.250 \\
\hline Midwest & 0.390 & 0.019 & $\begin{array}{l}< \\
0.001\end{array}$ & 1.477 & 1.422 & 1.534 \\
\hline Southeast & 0.469 & 0.019 & $<.001$ & 1.598 & 1.541 & 1.658 \\
\hline Lower unemployment & 0.037 & 0.013 & 0.003 & 1.038 & 1.012 & 1.064 \\
\hline Cheaper staple foods basket & -0.056 & 0.019 & 0.004 & 0.946 & 0.910 & 0.982 \\
\hline Higher income & -0.128 & 0.012 & $\begin{array}{l}< \\
0.001\end{array}$ & 0.880 & 0.860 & 0.900 \\
\hline Best Gini index & -0.030 & 0.011 & 0.006 & 0.970 & 0.950 & 0.991 \\
\hline Year (ref. 2013) & & & $<.001$ & & & \\
\hline 2014 & -0.006 & 0.016 & 0.685 & 0.994 & 0.964 & 1.025 \\
\hline 2015 & 0.845 & 0.013 & $<.001$ & 2.329 & 2.269 & 2.391 \\
\hline 2016 & -0.083 & 0.015 & $<.001$ & 0.921 & 0.894 & 0.947 \\
\hline Constant & -1.003 & 0.028 & $<.001$ & 0.367 & & \\
\hline I's ratio; Cl: Confid & & & & & & \\
\hline
\end{tabular}

Residing in a city with a lower unemployment rate increases the chance of having a higher LS score by $3.8 \%(\mathrm{OR}=1.038,95 \% \mathrm{Cl} 1.012-1.064)$; however, being a resident of a city with a cheaper staple foods 
basket decreases the chance of having a higher LS score by $5.4 \%(\mathrm{OR}=0.946,95 \% \mathrm{Cl} 0.910-0.982)$. Presenting higher income decreases the chance of presenting a higher LS by $12 \%(\mathrm{OR}=0.880,95 \% \mathrm{Cl}$ $0.860-0.900)$; the same behavior of the Gini index, which decreases by $3 \%$ the chance of presenting higher LS as the index increases.

2013 served as a reference year; 2014 did not evince statistical significance $(p=0.685)$; and 2015 was the best year in relation to lifestyle because the chance of evincing a better lifestyle increased 2.329-fold. However, there was a decline in lifestyle in 2016 because the chance of presenting a better lifestyle decreased by $7.9 \%$. In addition, a downward trend occurred over time ( $p$ trend $<0.001$ ).

By scrutinizing the indicators that make up the score, it was found that " $5 x$ per week fruit consumption" remained stable in 2013 (68.8\%) and 2014 (68.4\%), increased up to 71\% in 2015, and decreased to 67.6\% in the following year.

Further, there was an increase in the percentage of "Physical activity during leisure" in 2015 (20.9\%), followed by a decrease to $18.1 \%$ in 2016, after a period of stabilization in 2013 (19.5\%) and 2014 (19.6\%).

Physical exercise showed a steady annual increase, scoring $49.6 \%$ in 2013 , followed by $50.9 \%$ and $51.9 \%$ in 2014 and 2015, respectively, and ending with 54.5\% in 2016.

The indicator "Watching TV 5x per week" recorded a sharp drop between the years $2013(27.9 \%)$ and $2015(22.7 \%)$, as well as the consumption of soft drinks, which went from stable values in $2013(19.5 \%)$ and $2014(19 \%)$ to $17.3 \%$ in 2015.

On evaluating the score, 2015 is the year that presents a differentiated curve, reaching the mark of $53.4 \%$, almost $20 \%$ higher in comparison to the other years.

\section{Discussion}

Maintaining a healthy lifestyle and being physically active is a multifactorial result and is also influenced by socioeconomic conditions. Therefore, investigating changes in a society's lifestyle from an epidemiological perspective requires the observation of a set of variables that may or may not be clearly perceptible.

According to Triaca ${ }^{14}$, studies covering themes such as health and economy use unemployment and mortality as main outcomes. Further, most studies showed a pro-cyclical trend in their findings (i.e., a decrease in certain behavior following worsening of economic conditions).

This is the trend found by Hone et al ${ }^{15}$, who analyzed the effects of economic recession on mortality rate in 5565 Brazilian municipalities between 2012 and 2017, in a longitudinal study that found a direct correlation between unemployment and a percentage increase in national mortality rates, as well as between higher mortality rates among black individuals (black or brown) and greater protection against mortality in locations with better access to social protection programs. 
However, in some cases,an anti-cyclic pattern is observed (i.e., inverse association of behavior with economic indicators). So, if the economy is shrinking and smoking increases, this is an anti-cyclical pattern. However, if the economy faces a downward turn and smoking also decreases, it is a pro-cyclical pattern 4,5 .

In the study developed by $\mathrm{Xu}^{6}$, using a combination of public US government data, with men between 25 and 55 years, and in two different time periods (1984-2005 and 1976-2001), the increase in working hours as a result of the economic expansion showed a direct association with the increase in cigarette consumption, in a pro-cyclical pattern. Under another perspective, the study of Filippidis et al. ${ }^{9}$ analyzed the impact of the great recession of 2008 on the habits of the Greek population between 2006 and 2011 , with a sample of 3503 subjects. Conflicting data findings demonstrate that the impact of lifestyle on cardiovascular risk indicators may vary within the same locality when there is a stratification of society into socioeconomic classes. They revealed an increase in physical activity and a decrease in smoking and alcohol consumption in all socioeconomic strata, while there was a decrease in vegetable consumption, especially in classes with lower purchasing power.

These findings, at first, converge with the evidence that points to a pro-cyclical trend of health indicators during economic crises. However, the decline in vegetable consumption indicates the opposite, mainly because it was observed in the most impoverished classes of Greek society; that is, in the same country and during the same timeframe, pro- and anti-cyclic patterns were identified, depending on the variables that were analyzed.

Mattei et al. ${ }^{16}$ conducted a study using data from the National Statistical Institute of Italy; the data revealed anti-cyclical tendencies when the levels of obesity and smoking between pre (2000-2007) and post-crisis years (2008-2015)were statistically compared; an increase in these indicators was observed after the great recession.

What these studies have in common is the use of a comprehensive approach, avoiding the option to use mortality and unemployment as main variables and using other factors in the analysis. We also opted for this standard in our study.

In the case of Brazil, Triaca ${ }^{14}$ used non-parametric statistical analysis and a broad set of variables were analyzed to evaluate changes in lifestyle and the health indicators of the country's population in at least two periods of economic crisis, covering the space between 1992 and 2014. The findings evinced an anticyclical trend in the early 90 s up to 1995, with a worsening in health indicators strongly related to worsening in economic indicators; however, there was a change to a pro-cyclical pattern from 2004 to 2014 , when the aggravation of economic indicators was associated with improvement in mortality and health indicators.

The data found by Triaca ${ }^{14}$ converge with the most recent literature, confirming oscillations in the relation between economic and health indicators dependent on the moments in which countries are 
confronted by economic crises and also on each country's level of economic development $5,17,18$.

The present study also points to oscillations between anti-cyclic and pro-cyclic patterns depending on the historical cut adopted. In this analysis, 2013 and 2014 presented anti-cyclical tendencies; although these years preceded the crisis period, they still presented favorable economic data. Thus, with a favorable economic situation, there was a slight improvement in the score.

However, after 2014, even with the onset of recession in the Brazilian economy, the increase in the unemployment rate, and the already sharp rate of informality, the trends in quality of life standards of the general population were not sharply affected, especially in regions with higher MHDI, a fact corroborated by the findings demonstrated in Table 2 and Fig. 1.

Thus, we found a prominent pro-cyclical trend in 2015, with a significant improvement in health indicators that make up the LS even during the acute period of the economic crisis. Another important factor to be highlighted is that trends in 2015 were directly influenced by two major sporting events held in the country: the Football World Cup in 2014 and the Summer Olympics in 2016, which, according to Lima et al. ${ }^{19}$,could generate economic benefit and improve the standard of living of the population. However, data regarding the period after the Olympic Games were not evaluated, which makes it difficult to identify a prolonged benefit or an association with changes in the lifestyle of the post-event population.

Thus, an opposite trend with regard to the score's progression and the national panorama's macro and microeconomic deterioration as evinced by our analysis could be explained by a socioeconomic reserve built in earlier years, which prevents a marked degradation in the quality of life of the Brazilian population even if it occurs, as is noticeable by observing its correlation with the rate of vacancy and increase in the staple foods basket.

It is also possible to relate this change to a pro-cyclical pattern in 2015 with sporting events. However, the data found for the year 2016 show that this trend is not sustained and that the LS returns to the same standards as in 2013 in a new turn to the anti-cyclical pattern, with a worsening in health indicators following the worsening in economic indicators. This can be explained by the hypothesis raised by Oliveira ${ }^{20}$ that the sectors benefiting from mega-events are unable to leverage the economy a thesis that can be confirmed by Brazil's condition after the sporting mega-events.

Hypothetically, the Brazilian socioeconomic advances since 2002, with the peak of this virtuous cycle between the years 2008 and 2014 and a short period of full employment, decreased inequality, and overcoming of chronic problems such as hunger and extreme poverty ${ }^{21,22}$ may have contributed to protecting the population from the more pronounced deleterious effects of an economic crisis in the initial year. However, this effect seems to be limited because either the previous socioeconomic gain was insufficient in itself or the effects of the crisis were strong enough to increase social vulnerability, justifying the return of the anti-cyclical pattern. 
2015 presented the greatest impact in the regression model, which makes clear its relevance as the year that escaped the anti-cyclical pattern presented in the other years. In the midst of a political and economic crisis, 2015 presented an improvement in most health-related indicators with which we formulated the LS. Consequently, the reason for the curve shift was descriptively identified without, however, identifying a causal relation that could explain these findings.

Two hypotheses have been put forth to explain the behavior of the year 2015. First, being the first year of crisis and considering that there was a virtuous economic cycle in the previous decade, the population had not yet undergone major negative changes in their pattern and lifestyle during this year. Second, major sporting events such as the Football World Cup in 2014 and the preparations for the Summer Olympics scheduled for 2016 resulted in an improvement in the quality of life and a more active lifestyle and healthier diet, which positively impacted the score of 2015, an interlude between these years.

However, this effect was transient with the aggravation of the economic and the political crisis and a strong increase in unemployment and inflation, represented in the increase in the value of the staple foods basket, as well as a decrease in average per capita income. Hence, the anti-cyclical pattern becomes present, but this time with a direct negative relation, that is, an economic degradation directly linked with a worsening in health indicators and quality of life.

Further, in our model, the region within a country where one resides is an important factor, having a great weight within the statistical model ( $\beta$ Northeast: 0,$046 ; \beta$ South: 0,$181 ; \beta$ Midwest: 0,$390 ; \beta$ Southeast: 0.469 ); it was identified that the regions with the highest HDI (northeast: 0,663; south: 0,754; Midwest: 0.757; southeast: 0.766 ) are those with the highest direct association with the LS (northeast: 1.047; south: 1.198; midwest: 1.477; southeast: 1.598). This outcome seems to represent the country's structure of social and economic inequality with strong historical roots ${ }^{23}$.

\section{Conclusion}

It is concluded, therefore, that the economic crisis experienced by Brazil during 2013-2016 impacted the lifestyle of adults living in Brazilian state capitals. Further, pro-cyclic and anti-cyclic patterns can be observed in the same population, depending on which variables are analyzed and at what time.

In the case of Brazil, the economic crisis that initially began in 2015 had a negative impact on the population over time, but these effects were only observed in the second year of crisis, being preceded by a temporary improvement in indicators. Therefore, years of socioeconomic development can lessen the negative effects of a crisis on the lifestyle of the population for a short period.

\section{Declarations}

\section{Ethics approval and consent to participate.}


This study was done with secondary data and obtained from a public domain database obtained from the website of federal, state, and municipal government agencies in Brazil. Therefore, according to Brazilian national guidelines, approval is not applied to the ethics committee.

\section{Consent for publication.}

Not applicable.

\section{Availability of data and materials}

All data generated or analyzed during this study are included in this published article. The Debt data of the States and Municipalities were visualized by the public database https://www4.bcb.gov.br/fis/dividas/Imunicipios.asp.

DataSUS/Vigitel data were obtained from the Public Database of the Ministry of Health at the address http://tabnet.datasus.gov.br/cgi/vigitel/vigteldescr.html.

Finally, all data related to federal socioeconomic indicators were obtained directly from the database of the Brazilian Institute of Geography and Statistics (IBGE) available at:

https://downloads.ibge.gov.br/downloads_estatisticas.html .

\section{Competing interest}

The authors declare that they have no competing interests.

\section{Funding}

None.

\section{Author's contributions}

Sonny Bezerra, Denilson Menezes and Michele Oliveira compiled data. Sonny Bezerra, Denilson Menezes and Emanuel Salvador conceptualized the study, analyzed data, produced the figures and tables, and wrote the original draft of the manuscript. Emanuel Salvador provided statistical guidance for interpreted data and input on the analysis and edited early drafts of the manuscript. All authors contributed to subsequent drafts of the manuscript and provided critical interpretation of the results and approved the manuscript for publication and Levy Rezende also translated the manuscript after review.

\section{Acknowledgements}

Not applicable

\section{References}


1. Malta DC, Reis AACd, Jaime PC, Morais Neto OLd, Silva MMAd, Akerman M. O SUS e a Política Nacional de Promoção da Saúde: perspectiva resultados, avanços e desafios em tempos de crise. Ciência \& Saúde Coletiva. 2018;23:1799-809; doi: 10.1590/1413-81232018236.04782018.

2. Malta DC, Moura EC, Castro AMd, Cruz DKA, Morais Neto OLd, Monteiro CA. Padrão de atividade física em adultos brasileiros: resultados de um inquérito por entrevistas telefônicas, 2006. Epidemiologia e serviços de saúde. 2009;18(1):7-16; doi: 10.5123/s1679-49742009000100002.

3. Mielke GI, Hallal PC, Rodrigues GBA, Szwarcwald CL, Santos FV, Malta DCJEeSdS. Prática de atividade física e hábito de assistir à televisão entre adultos no Brasil: Pesquisa Nacional de Saúde 2013. 2015;24:277-86.; doi: 10.5123/s1679-49742015000200010.

4. Ruhm CJ. Are recessions good for your health? The Quarterly journal of economics. 2000;115(2):617-50.

5. Ruhm CJ. Recessions, healthy no more? Journal of health economics. 2015;42:17-28; doi: 10.1016/j.jhealeco.2015.03.004.

6. Xu X. The business cycle and health behaviors. Social Science \& Medicine. 2013;77:126-36.

7. Di Pietro G. Revisiting the impact of macroeconomic conditions on health behaviours. Economics \& Human Biology. 2018;28:173-81.

8. Shin J-H, Lee G, Kim J-S, Oh H-S, Lee K-S, Hur Y, et al. Effects of the 2008 global economic crisis on national health indicators: results from the Korean National Health and Nutrition Examination Survey. Korean journal of family medicine. 2015;36(4):162; doi: 10.4082/kjfm.2015.36.4.162.

9. Filippidis FT, Schoretsaniti S, Dimitrakaki C, Vardavas $\mathrm{Cl}$, Behrakis P, Connolly GN, et al. Trends in cardiovascular risk factors in Greece before and during the financial crisis: the impact of social disparities. The European Journal of Public Health. 2014;24(6):974-9; doi: 10.1093/eurpub/cku028.

10. Macy JT, Chassin L, Presson CC. Predictors of health behaviors after the economic downturn: a longitudinal study. Social science \& medicine. 2013;89:8-15; doi: 10.1016/j.socscimed.2013.04.020.

11. BRASIL. Vigilância de fatores de risco e proteção para doenças crônicas por inquérito telefônico: Vigitel. In: Saúde Md, editor. Datasus. http://tabnet.datasus.gov.br/cgi/vigitel/vigteldescr.html. Acessed 04 May 2018.

12. BRASIL. Downloads: IBGE. In: Economia Md, editor. Instituto Brasileiro de Geografia e Estatística. 2018. https://downloads.ibge.gov.br/downloads_estatisticas.html. Acessed 08 Dec 2018.

13. BRASIL. Endividamento dos Estados e Municípios. In: Economia Md, editor. Banco Central do Brasil. https://www4.bcb.gov.br/fis/dividas/Imunicipios.asp. Acessed 10 Dec 2018.

14. Triaca LM. Condições macroeconômicas e saúde. 2018.

15. Hone T, Mirelman AJ, Rasella D, Paes-Sousa R, Barreto ML, Rocha R, et al. Effect of economic recession and impact of health and social protection expenditures on adult mortality: a longitudinal analysis of 5565 Brazilian municipalities. The Lancet Global Health. 2019;7(11):e1575-e83; doi: $10.1016 /$ s2214-109x(19)30409-7. 
16. Mattei G, De Vogli R, Ferrari S, Pingani L, Rigatelli M, Galeazzi GM. Impact of the economic crisis on health-related behaviors in Italy. International Journal of Social Psychiatry. 2017;63(7):649-56; doi: $10.1177 / 0020764017726097$.

17. Nasser B. Economia regional, desigualdade regional no Brasil e o estudo dos eixos nacionais de integração e desenvolvimento. 2000.

\section{Figures}

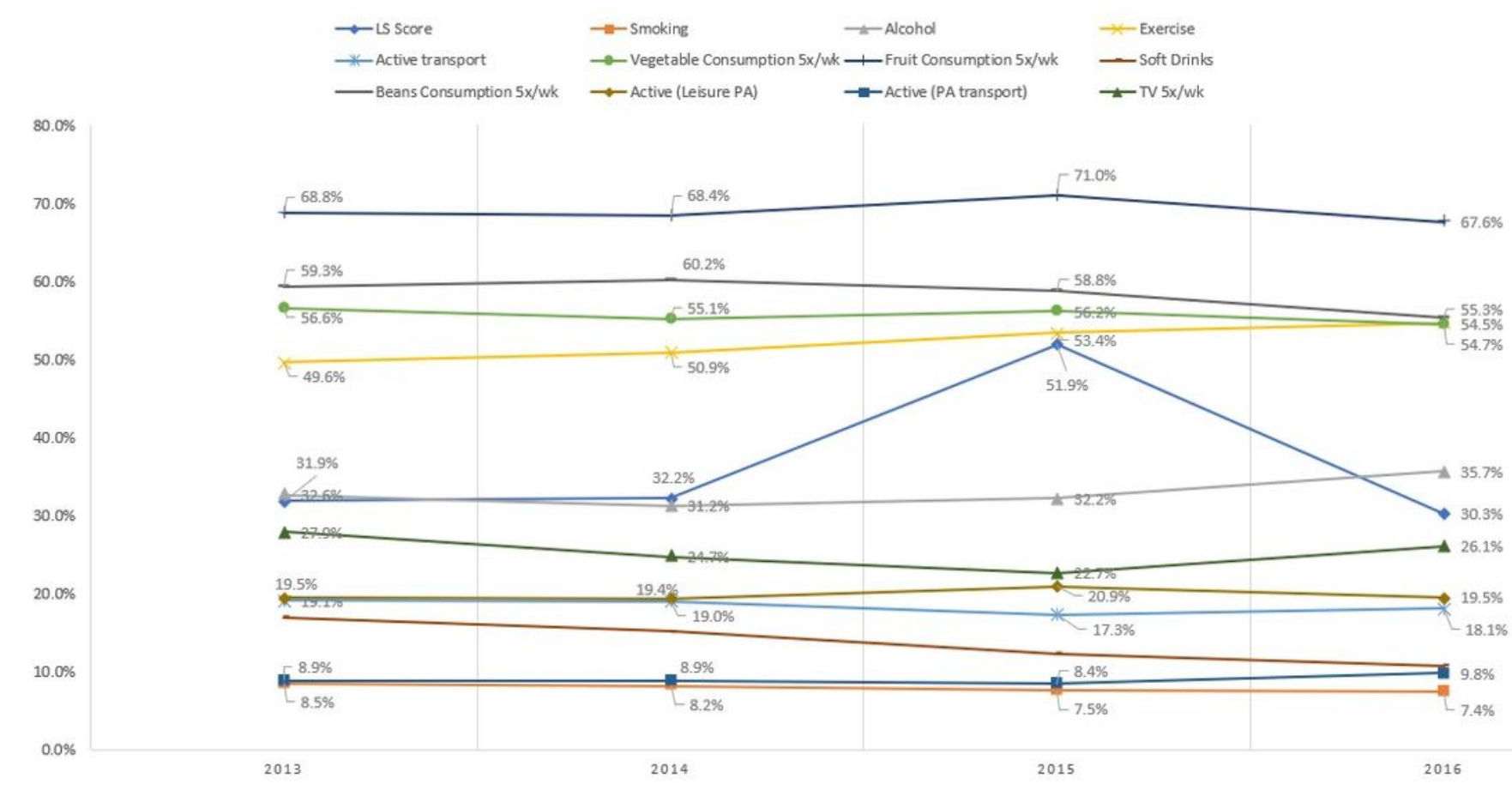

\section{Figure 1}

Behavior of health indicators (EQL) between 2013 and 2016 